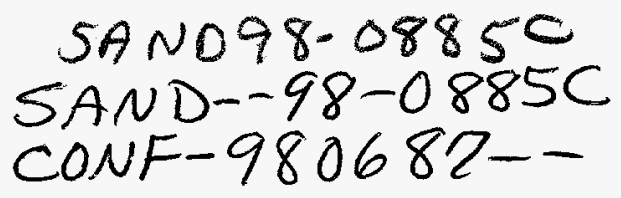

\title{
The Technology and Applications of Selective Oxidation
}

\author{
Kent D. Choquette, K. M. Geib, and H. Q. Hou \\ Center for Compound Semiconductor Science and Technology \\ Sandia National Laboratories \\ Albuquerque, NM 87185-0603 \\ D. Mathes and Robert Hull \\ University of Virginia \\ Charlottesville, VA
}

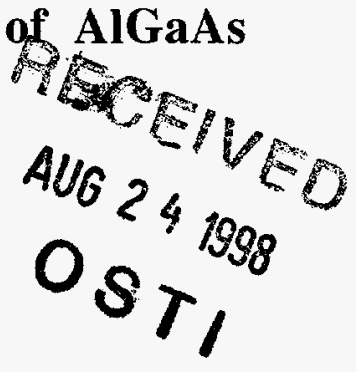

Wet oxidation of AlGaAs alloys, pioneered at the University of Illinois a decade ago, recently has been used to fabricate high performance vertical-cavity surface emitting lasers (VCSELs). The superior properties of oxide-confined VCSELs has stimulated interest in understanding the fundamentals of wet oxidation. We briefly review the technology of selective oxidation of III-V alloys, including the oxide microstructure and oxidation processing as well as describe its application to selectively oxidized VCSELs.

\section{A. Introduction}

Wet oxidation of AlAs was first reported in 1979, although the native (Gibbsite) oxide phase was formed at the low oxidation temperature used $\left(100^{\circ} \mathrm{C}\right)[1]$. Ten years later during studies of atmospheric degradation of AlAs, it was discovered by researchers at the University of Illinois that wet oxidation of Al-containing semiconductors (AlGaAs, AllnAs, AlGaInP, etc.) at temperatures above $\approx 300{ }^{\circ} \mathrm{C}$ produces a mechanically robust oxide with a low refractive index [2]. The utility of this oxide was initially demonstrated in a variety of edge emitting laser structures where the oxide layers provide both index-guiding and buried current apertures [3-5].

Oxidized AlGaAs layers have also recently been introduced within vertical cavity surface emitting lasers (VCSELs) [6,7]. Selectively oxidized VCSELs have exhibited superior laser performance due to the efficient electrical and optical confinement afforded by the buried oxide layers. Other applications of wet oxidized AlGaAs have included high index contrast distributed Bragg reflector mirrors [8], birefringent optical waveguides [9], buried microlenses [10], and metalinsulator-semiconductor transistors [11]. Nevertheless as shown in Fig. 1 , research on the oxidation of III-V alloys as measured by journal publications has been driven over the past few years by the significant interest in selectively oxidized VCSELs. Understanding the microstructure and processing of oxides converted from AlGaAs is essential for the development of a robust fabrication technology for optoelectronic devices [12]. We briefly review selective wet oxidation of AlGaAs alloys and its application to VCSEL fabrication.

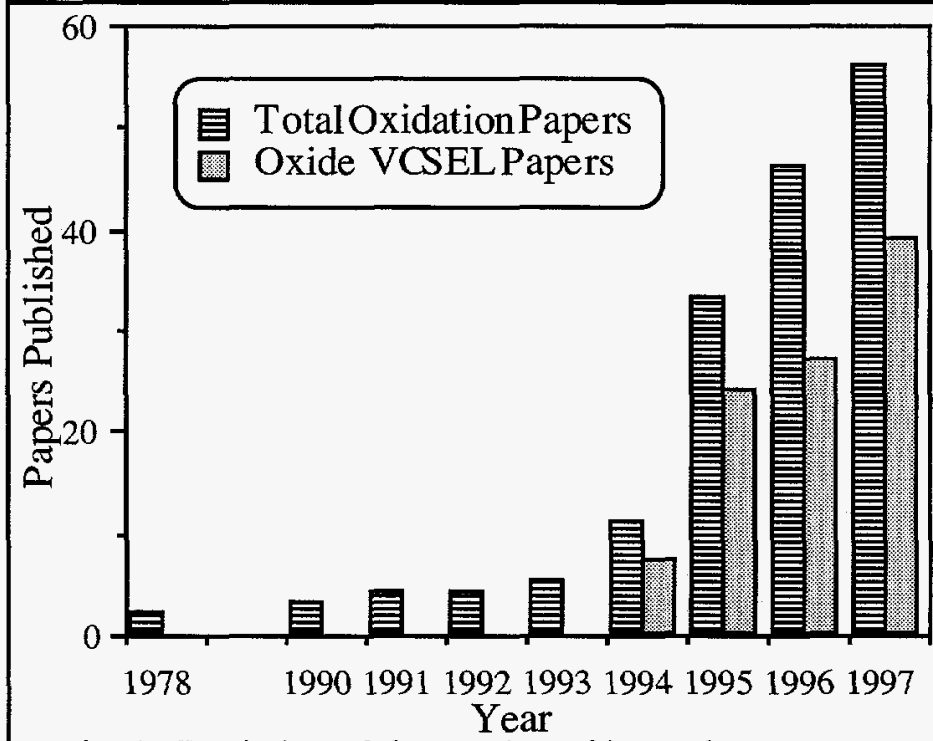

Fig. 1. Depiction of the number of journal papers on wet oxidation of AlGaAs and selectively oxidized VCSELs. 


\section{DISCLAIMER}

This report was prepared as an account of work sponsored by an agency of the United States Government. Neither the United States Government nor any agency thereof, nor any of their employees, makes any warranty, express or implied, or assumes any legal liability or responsibility for the accuracy, completeness, or usefulness of any information, apparatus, product, or process disclosed, or represents that its use would not infringe privately owned rights. Reference herein to any specific commercial product, process, or service by trade name, trademark, manufacturer, or otherwise does not necessarily constitute or imply its endorsement, recommendation, or favoring by the United States Government or any agency thereof. The views and opinions of authors expressed herein do not necessarily state or reflect those of the United States Government or any agency thereof. 


\section{DISCLAIMER}

Portions of this document may be illegible electronic image products. Images are produced from the best available original document. 


\section{B. Oxide Microstructure}

Cross section transmission electron microscopy (TEM) has been applied to characterize the microstructure of buried oxide layers as shown in Fig. 2. Electron diffraction patterns indicate that the oxide converted from $\mathrm{AlGaAs}$ is an amorphous solid solution of $\left(\mathrm{Al}_{\mathrm{X}} \mathrm{Ga} 1-\mathrm{x}\right)_{2} \mathrm{O}_{3}$ [13]. The bright field image in Fig. 2 reveals only granular amorphous contrast within the oxide, with an $\approx 17 \mathrm{~nm}$ thick interface zone at the oxide/semiconductor interface. No extended defects are

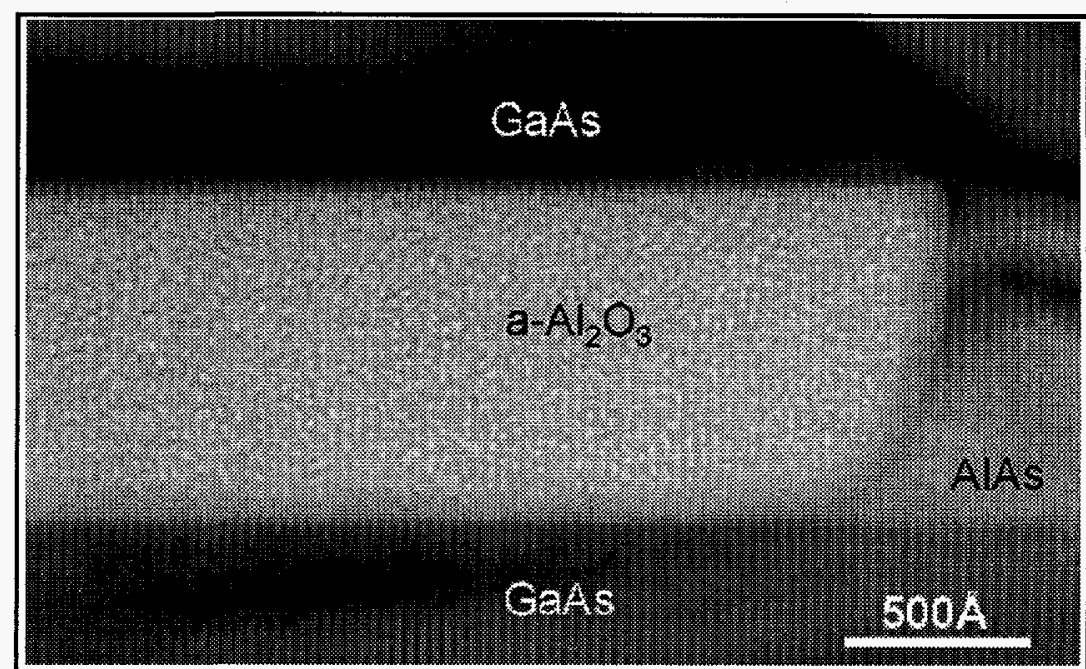

Fig. 2. Cross section TEM image of an amorphous oxide layer converted from $100 \mathrm{~nm}$ thick AlAs surrounded by GaAs layers. apparent along the oxide/semiconductor interfaces and a smooth transition over several lattice constants is apparent between the oxide and semiconductor.

The thickness of an oxide formed at temperatures above $300^{\circ} \mathrm{C}$ tends to be reduced compared to the original semiconductor layer [2]. The linear shrinkage is measured to be 12 to $13 \%$ in the amorphous oxide layers converted from AlAs [8]. However, shrinkage for oxidized

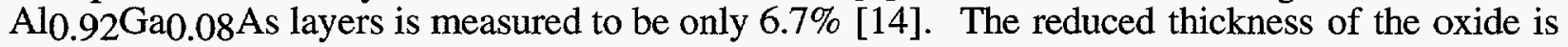
thus dependent upon composition of the converted semiconductor and can result in strain fields at the oxide terminus [15].

\section{Oxidation Processing}

To develop a manufacturable wet oxidation technique, the influence of process parameters such as gas flow, gas composition, temperature, $\mathrm{Al}$ composition, and layer thickness on the rate of oxidation have been examined [12,16]. The lateral oxidation has a linear oxidation rate which obeys an Arrhenius temperature dependence. A strong compositional dependence of the oxidation rates is shown in Fig. 3(a) where the oxidation rate of $\mathrm{Al}_{\mathrm{X}} \mathrm{Ga} 1-\mathrm{X}$ As for $\mathrm{x}$ varying from 1 to 0.84 , changes by more than 2 orders of magnitude [7]. It is this oxidation selectivity which can be exploited for the fabrication of buried oxide layers within a VCSEL; with minute changes of Ga concentration, specific or multiple AlGaAs layer(s) can be selected out to form buried oxide layers for electrical and optical confinement (see Fig. 5).

The thickness of the semiconductor layer to be oxidized can also influence its oxidation rate as shown in Fig. 3(b). For thickness $\geq 60 \mathrm{~nm}$, a relatively constant lateral oxidation rate is observed; for thinner layers the oxidation rate dramatically decreases. Comparing Figs. 3(a) and 3(b), it is obvious that the oxidation rate dependence on thickness can compensate for the compositional dependence: thin layers of AlAs may oxidize slower than thick layers of AlGaAs.

Finally, the composition of the surrounding layers will affect the oxidation rate and shape of the oxide terminus through diffusion and supply of reactants [17]. For example as shown in Fig. 4, a rapidly oxidizing layer can supply reactants to its surrounding layers such that significant vertical oxidation into the adjoining layers occurs. Fig. 4 shows a tapered oxide terminus which results from the oxidation of a $14 \mathrm{~nm}$ thick Al0.98Ga0.02As layer embedded within a thicker Al0.92Ga0.08As layer. The effective lateral oxidation rate of the Al0.92Ga0.08As layer in Fig. 12 is enhanced by a factor of 2 over the rate predicted from Fig. 3(a) due to vertical oxidation originating from exposure to reactants supplied from the thin oxidized Al0.98Ga0.02As layer. 

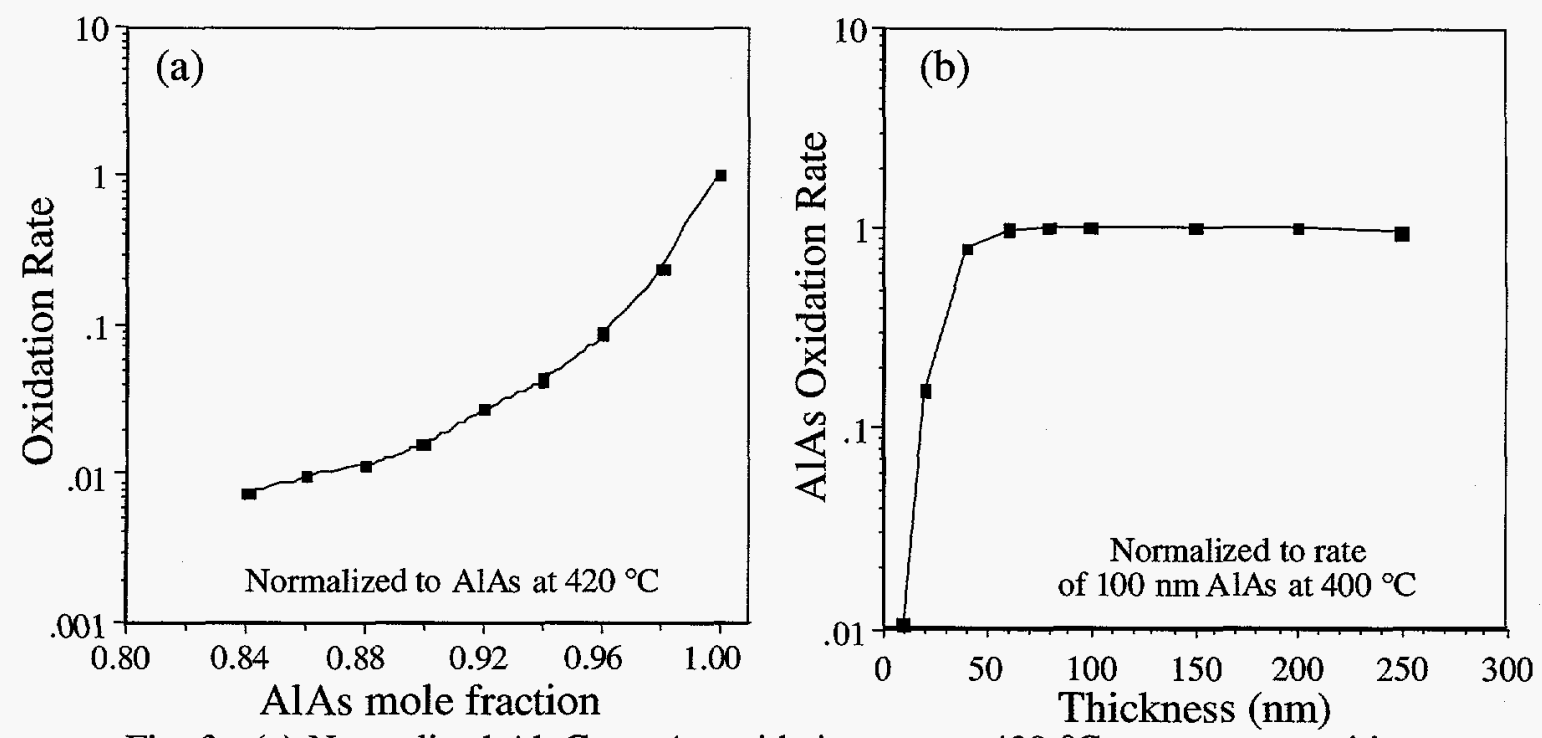

Fig. 3. (a) Normalized $\mathrm{Al}_{\mathrm{X}} \mathrm{Ga} 1-\mathrm{x}$ As oxidation rate at $420^{\circ} \mathrm{C}$ versus composition;

(b) normalized oxidation rate of AlAs at $400^{\circ} \mathrm{C}$ versus layer thickness.

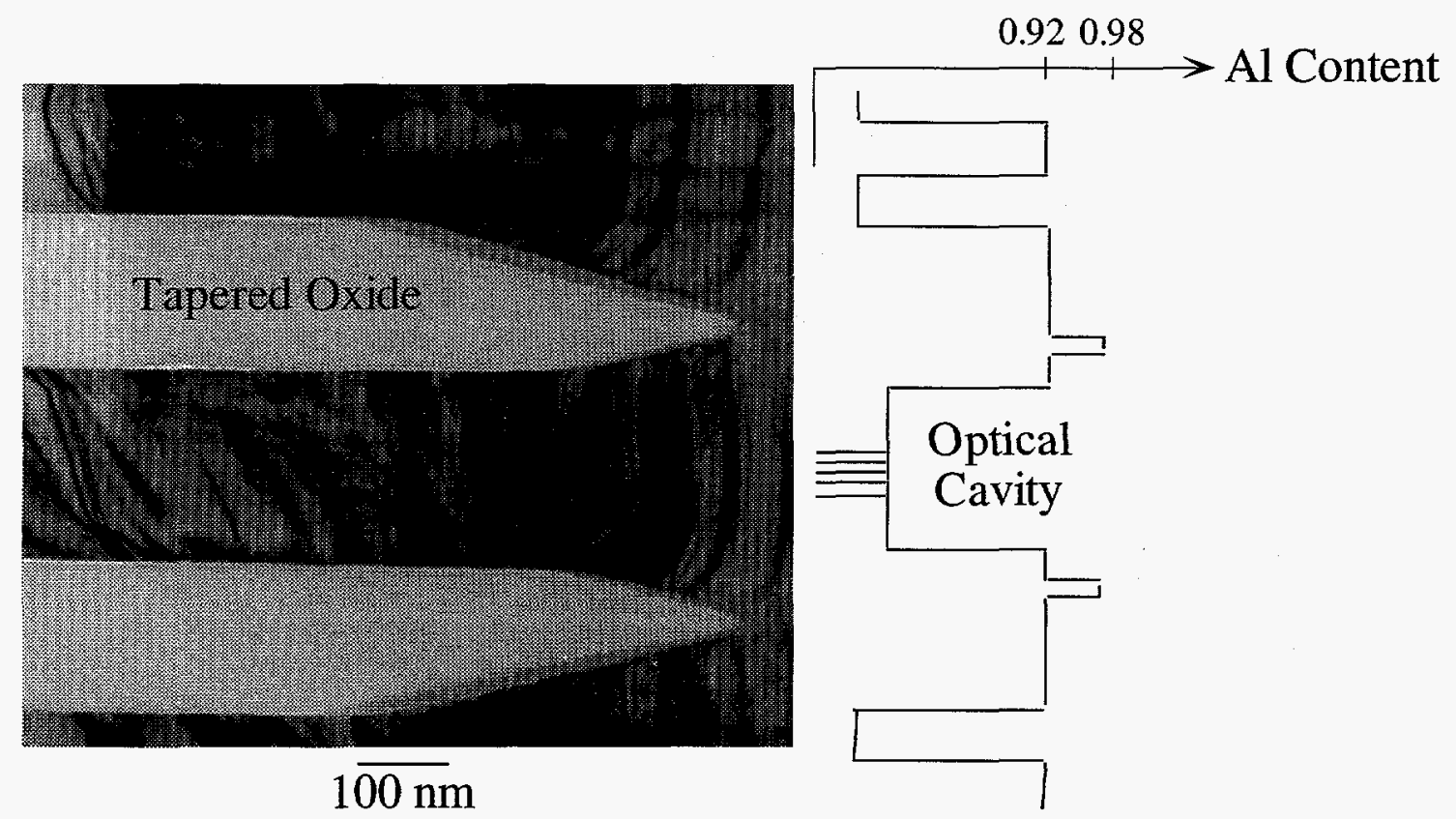

Fig. 4. Cross section TEM image of two tapered oxides (adjacent to optical cavity) produced from $14 \mathrm{~nm}$ thick $\mathrm{Al}_{0.98} \mathrm{Ga0} 02 \mathrm{As}$ embedded within a $160 \mathrm{~nm}$ thick $\mathrm{Al}_{0.92} \mathrm{Ga} 0.08$ As layer.

\section{Selectively Oxidized VCSELs}

Significant performance advances have been achieved from selectively oxidized VCSELs which, as depicted in Fig. 5, incorporate one or more buried oxide apertures for efficient electrical and optical confinement $[7,18]$. These devices are fabricated by first growing the material by metalorganic vapor phase epitaxy. A mesa is etched to expose the sidewalls for oxidation as sketched in Fig. 5. The lateral extent of oxidation within the laser mesa can be controlled by the oxidation time [18]. Moreover, through design of the composition of the various layers within the VCSEL, the oxidation profile within the laser cavity can be tailored to affect the optical confinement and/or electrical injection into the laser. 


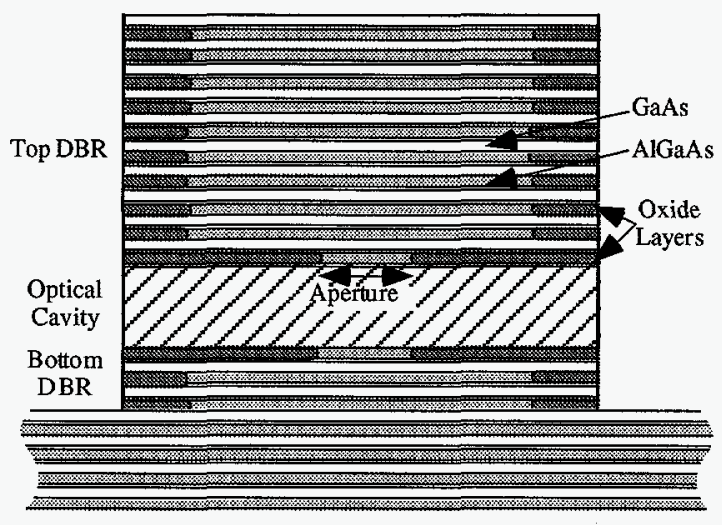

Fig. 5. Selectively oxidized VCSEL composed of GaAs/AlGaAs multilayers and buried oxide layers.

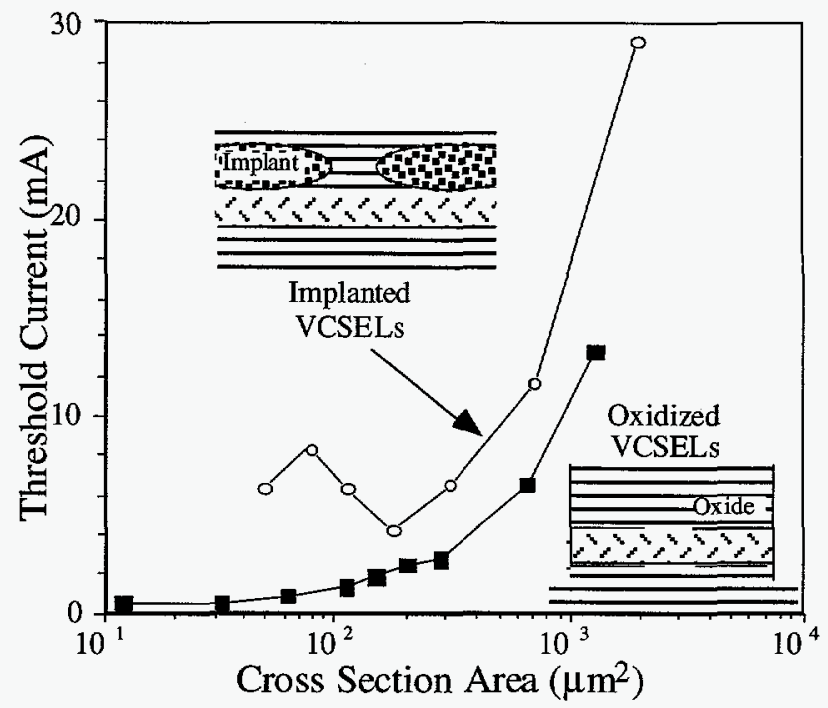

Fig. 6. Comparison of threshold current of implanted and selectively oxidized VCSELs.

The improved electrical confinement arising from the oxide apertures is particularly manifest as reduced threshold current and voltage compared to other VCSEL structures [19]. In Fig. 6 we compare selectively oxidized and ion implanted $850 \mathrm{~nm}$ VCSELs with various cavity sizes fabricated from the same epitaxial wafer. The ion implanted VCSELs rely on ion implantation to render a region around the laser nonconductive, thus defining the laser cavity. The reduced threshold current for the selectively oxidized VCSELs in Fig. 6 arises due to the improved electrical confinement and reduced current spreading. Moreover, the refractive index of the buried oxide layer changes from 3.0 for the original $\mathrm{AlGaAs}$ layer to $\approx 1.6$ for the oxidized layer. This induces a significant index difference between the laser cavity and the region surrounding the laser thus providing index-guiding optical confinement. The ion implanted VCSELs in Fig. 6 do not exhibit monotonic decreasing threshold current with decreasing size, due to increased diffraction loss. In contrast, the index-guiding in the selectively oxidized VCSELs produces a monotonic decrease of the threshold currents in Fig. 6. Selectively oxidized VCSELs have also demonstrated high power conversion efficiency [20], high output power, and high speed modulation [21].

\section{E. Conclusion}

Further work will certainly be required to develop selective wet oxidation of AlGaAs into a manufacturing technology for VCSELs or other microelectronic/photonic devices. Although selective oxidation has been shown to be a stable fabrication process, in order to scale up to full wafer manufacture, issues pertaining to reproducibility and uniformity obviously remain. Moreover, developing a means to photolithographically predefine the length of the oxide layer within a given device structure would be advantageous. Finally, analogous to process simulators available for Si oxidation, it will be necessary to develop predictive models of the oxidation of AlGaAs. In spite of these remaining challenges, the motivation to develop a wet oxidation technology is clearly driven by the demonstrated high performance of selectively oxidized VCSELs. Therefore, to meet the requirements of emerging applications, selective wet oxidation of AlGaAs may play an important role in the manufacture of high performance VCSELs.

Sandia is a multiprogram laboratory operated by Sandia Corporation for the United States Department of Energy under contract No. DE-AC04-94AL85000. 


\section{References}

[1] W. T. Tsang, Appl. Phys. Lett., 1978, vol. 33, 426.

[2] J. M. Dallesasse, N. Holonyak, Jr., A. R. Sugg, T. A. Richard, and N. El-Zein, Appl. Phys. Lett., 1990 , vol. 57, 2844.

[3] J. M. Dallesasse and N. Holonyak, Jr., Appl. Phys. Lett., 1991, vol. 58, 394.

[4] F. A. Kish, S. J. Caracci, N. Holonyak, Jr., J. M. Dallesasse, K. C. Hsieh, M. J. Ries, S. C. Smith, and R. D. Burnham, Appl. Phys. Lett., 1991, vol. 59, 1755.

[5] S. A. Maranowski, A. R. Sugg, E. I. Chen, and N. Holonyak, Jr., Appl. Phys. Lett., 1993, vol. 63, 1660.

[6] D. L. Huffaker, D. G. Deppe, K. Kumar, and T. J. Rogers, Appl. Phys. Lett., 1994, vol. 65, 97.

[7] K. D. Choquette, R. P. Schneider, Jr., K. L. Lear, and K. M. Geib, Electron. Lett., 1994, vol. 30, 2043.

[8] M. H. MacDougal, H. Zhao, P. D. Dapkus, M. Ziari, and W. H. Steier, Electron. Lett., 1994, vol. $30,1147$.

[9] A. Flore, V. Berger, E. Rosencher, N. Laurent, S. Theilmann, N. Vodjdani, and J. Nagle, Appl. Phys. Lett., 1996, vol. 68, 1320.

[10] O. Blum, K. L. Lear, H. Q. Hou, and M. E. Warren, Electron. Lett., 1996, vol. 32, 1406.

[11] E. I. Chen, N. Holonyak, Jr., and S. A. Maranowski, Appl. Phys. Lett., 1995, vol. 66, 2688.

[12] K. D. Choquette, K. M. Geib, C. I. H. Ashby, R. D. Twesten, O. Blum, H. Q. Hou, D. M. Follstaedt, B. E. Hammons, D. Mathes, and R. Hull, J. Special Topics Quan. Electron., 1997, vol. $3,916$.

[13] R. D. Twesten, D. M. Follstaedt, and K. D. Choquette, SPIE Proc., 1997, vol. 3003, 56.

[14] R. D. Twesten, D. M. Follstaedt, K. D. Choquette, and R. P. Schneider, Jr., Appl. Phys. Lett., 1996, vol. 69, 19.

[15] K. D. Choquette, K. M. Geib, H. C. Chui, B. E. Hammons, H. Q. Hou, T. J. Drummond, and R. Hull, Applied Physics Letters, 1996, vol. 69, 1385.

[16] K. Geib, K. D. Choquette, H. Q. Hou, and B. E. Hammons, SPIE Proc., 1997, vol. 3003, 69.

[17] R. L. Naone, E. R. Hegbloom, B. J. Thibeault, and L. A. Coldren, Electron. Lett., 1997, vol. 33, 300.

[18] K. D. Choquette, K. L. Lear, R. P. Schneider, K. M. Geib, J. J. Figiel, and R. Hull, Photon. Tech. Letters, 1995, vol. 7, 1237.

[19] K. D. Choquette, K. L. Lear, R. P. Schneider, and K. M. Geib, Applied Physics Letters, 1995, vol. $66,3413$.

[20] K. L. Lear, K. D. Choquette, R. P. Schneider, Jr., S. P. Kilcoyne, and K. M. Geib, Electronics Letters, 1995, vol. 31, 208.

[21] K. L. Lear, A. Mar, K. D. Choquette, S. P. Kilcoyne, R. P. Schneider, Jr., and K. M. Geib, Electron. Lett., 1996, vol. 32, 457. 